\title{
Snapshots of Mathematics in Sub-Saharan Africa
}

\author{
Edited by Allyn Jackson and Carol Shubin
}

Mathematics knows no races or geographic boundaries; for mathematics, the cultural world is one country.

-David Hilbert

Mathematics is on the rise in Sub-Saharan Africa, where a critical mass of researchers and educators is developing. In October 2003, the Notices carried the article "The Challenge of Strengthening Mathematics in Africa" by Phillip A. Griffiths and Wandera Ogana. ${ }^{1}$ Since that time, there have been dramatic increases in the number of people engaged in mathematics education and research through research centers, conferences, international partnerships, collaborations, and exchanges. Many entities have contributed to these efforts, including African governments, government agencies of other countries, universities, international foundations, and individuals. Tremendous optimism and great potential coexist alongside serious political, social, and cultural challenges. ${ }^{2}$

Allyn Jackson, former senior writer and deputy editor of the Notices, is a freelance journalist and editor. Her email address is a11ynjacksn@gmai1.com.

Carol Shubin is professor of mathematics at California State University Northridge. Her email address is caro1. shubin@ csun. edu.

The assistance of Wilfrid Gangbo and Ricky Wolff in the preparation of this article is gratefully acknowledged. \footnotetext{
1 www . ams . org/notices/200309/commentary.pdf

${ }^{2}$ See the two reports prepared by the International Mathematical Union: Mathematics in Africa: Challenges and Opportunities, prepared by the IMU for the John Templeton Foundation, 2009, https://bit.1y/2JszQkt; and Mathematics in Africa: Challenges and Opportunities, prepared for the International Congress of Mathematicians in Seoul, Korea August 13-21, 2014, https:// bit. 1y/2HtLOOu.

For permission to reprint this article, please contact: reprint-permission@ams.org.

DOI: http://dx.doi.org/10.1090/noti1704
}

This article provides snapshots of experiences of several mathematicians who have done research and teaching in Sub-Saharan Africa. While each snapshot encapsulates the writer's personal viewpoint on mathematics in Africa, there is a common theme to them all: The interest in mathematics is there, but Africans need more opportunities and resources to develop the continent's talent base.

The purpose of this article is to inspire more mathematicians to help in the effort to build African mathematics. There are many ways to do this. You can spend a sabbatical term teaching, give a mini-course, attend a conference, encourage your university to provide tuition waivers or scholarships for African students, or consider inviting an African faculty member to your institution. You can contribute to funds for graduate student travel. You can be a mentor or publish an article with an African researcher in an African journal. You can support travel grant programs or the African Math Olympiad. Many suggestions are outlined in the sidebar at the end of this article.

Try Africa. It could change your life-and the lives of others.

\section{Augustin Banyaga}

\section{My Life and My Contributions to Building African Mathematics}

I was born in 1947 and raised in a village near Kigali, the Rwandan capital. At that time Rwanda was a Belgian colony. My parents were farmers, and my father occasionally worked as a bricklayer on construction sites. My parents had no formal education. But I was able to go to an elementary school in Kigali, walking several miles there and back home each day. There were no books to read. After school 
I spent the rest of the day helping with household work, like going to the river to bring water for the family. I used my free time walking and dreaming on my family's banana plantation. I was fond of nature: I collected dried flowers, butterflies, and beautiful quartz stones. I was fascinated by symmetry, which is the foundation of geometry. Maybe my love of symmetries and hence of geometry came from these early experiences. They were more important than what I was taught at school.

After these happy years, I was admitted to a high school located about thirty miles from the village, where I studied classics (Latin and Greek). I finished high school at a different institution near Kigali, where the main emphasis was on Latin and sciences. The mathematics curriculum was okay but not great. I did very well and finished first in my class in 1966. The following year, I received a government scholarship to go to Geneva, Switzerland, to study mining engineering. I didn't like my geology classes, but I loved the freshman linear algebra course, which was taught by Professor André Haefliger. Meeting this famous mathematician was the turning point of my life. Thanks to him, my heart completely turned to mathematics. I changed my major to mathematics and performed very well, finishing the equivalent of the bachelor's degree in 1971, in record time. Professor Haefliger agreed to be my doctoral advisor, and I finished my $\mathrm{PhD}$ thesis in 1976. My area of research was and remains in differential geometry/topology. I was the first Rwandan to hold a PhD in mathematics.

After my PhD, I wanted to go back to my native Rwanda. I applied for a position at the unique university in the country, the National University of Rwanda (NUR). After several months without a reply, I sent an application for a visiting position to the Institute of Advanced Study in Princeton. I got an immediate positive answer and went to the IAS in 1977.

I have always wanted to do mathematics in Africa. When I applied for the position at NUR, there were no Rwandan mathematicians. The university was functioning with expatriate faculty who held only bachelor's or master's degrees. This is why the NUR neglected my application: I was perceived as a threat. Ironically, at the same time they were rejecting me, Harvard University offered me a Benjamin Peirce Assistant Professorship. I was at Harvard from 1978 until 1982 and then moved to Boston University. In

Augustin Banyaga is professor of mathematics and a Distinguished Senior Scholar at Pennsylvania State University. His email address is banyaga@math.psu.edu. mathematics.
1984 I joined the faculty of my present institution, Penn State University.

In 1981, 1982, and 1983, I visited NUR as a UNESCO consultant and started a mathematics $\mathrm{PhD}$ program there. The program functioned for only a couple of years before dying off. One of my students from this program, Philippe Rukimbira, came to Penn State to finish his PhD under my supervision and is now a professor at Florida International University. In 1979 I took a leave of absence from Harvard to continue teaching in my $\mathrm{PhD}$ program in Rwanda. I asked people at NUR if it would be possible for me to maintain half a position in Rwanda, and the other half abroad. The answer was no. I then decided to settle in the US. I became a US citizen in 1995.

That same year I reconnected with Africa at the Fourth African Mathematical Union Pan-African Congress of Mathematics, in Ifrane, Morocco. There I met Jean-Pierre Ezin, a mathematician from Benin, who was the director of the Institut de Mathématiques et Sciences Physiques (IMSP) in Benin (see Figure 1). Professor Ezin invited me to the IMSP, and since then I have visited almost every year for over twenty years and even spent a sabbatical leave there.

The IMSP is a small graduate school that recruits students from all over Africa. Admission to the IMSP is extremely competitive: only

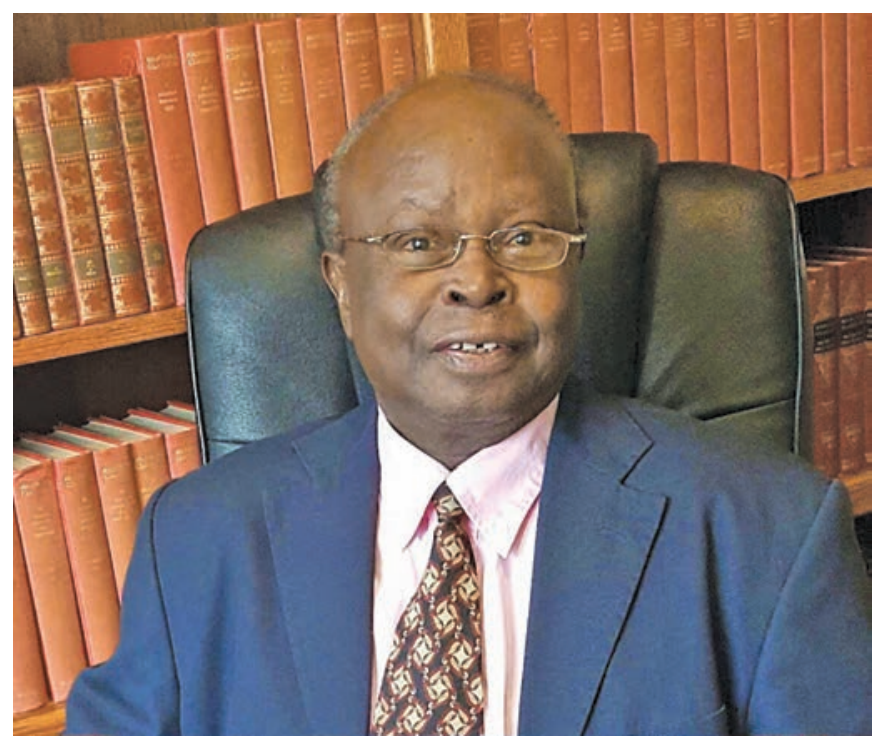

Augustin Banyaga is a Fellow of the African Academy of Sciences and the first Rwandan to hold a PhD in excellent and highly motivated students get in. Since its founding in the 1980 s, the IMSP has been supported by the Abdus Salam International Center for Theoretical Physics in Trieste, an organization that aims to build scientific research in the developing world. More recently, the IMSP won an award from the World Bank to host a "center of excellence." Since 1995, I have been a member of the IMSP Scientific Committee.

Over the course of my visits to IMSP, I gave sixteen graduate minicourses, of two to three weeks each, in my area of research: symplectic geometry, contact geometry, and Morse theory. Teaching at IMSP was a very enjoyable and rewarding experience. I had classes of fewer than 15 students, all of them very bright and highly motivated, comparable to the best students one gets in top universities in the US. Some of them finished their PhDs under my supervision. This was a difficult task because of the distance-I was at Penn State and they were in Africa-and we often had to work together over the internet. I published joint papers with some of my former students, as well as a book.

Over the last twenty years, I have also taught and done research at other African universities, including University 
of Botswana, University of Dakar, Universities of Yaounde and Dschang in Cameroon, University of Niamey in Niger, and University of Congo-Brazzaville. I have also visited AIMS Senegal, where I gave lectures and seminars and directed master's theses.

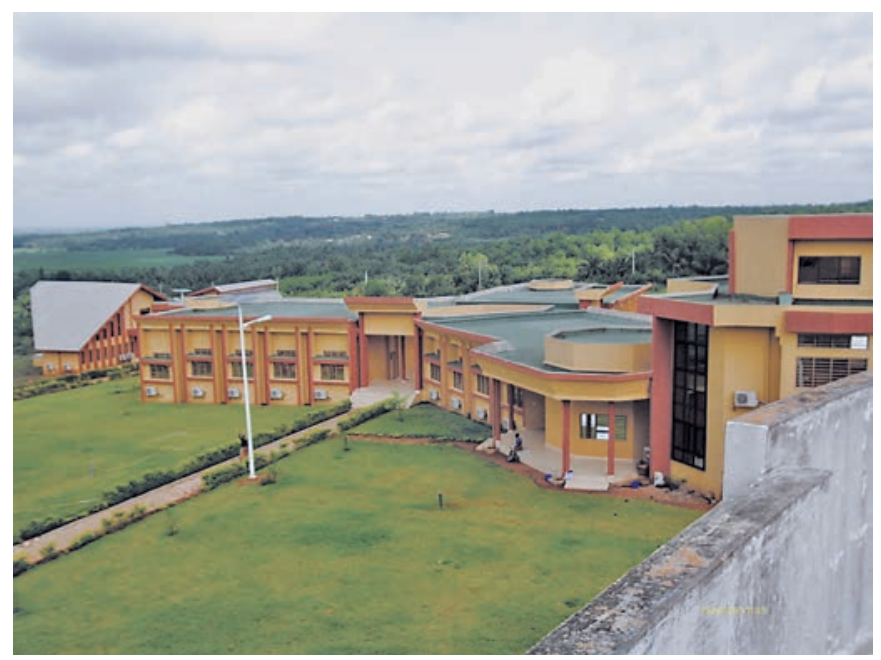

Figure 1: Pictured here is the Institut de Mathématiques et Sciences Physique (IMSP) in Benin. A small graduate school in mathematics that recruits students from all over Africa, IMSP recently won a World Bank award to host a "center of excellence."

I have been involved in other efforts to build mathematics in Africa, including creating research networks that sponsored conferences and workshops and serving on the selection committees for the African Mathematics Millennium Science Initiative (founded by Phillip Griffiths of the IAS) and for the Simons Foundation's Africa Mathematics Project. For many years, I have been on the editorial board of Afrika Matematika (the journal of the African Mathematical Union), the African Diaspora Journal of Mathematics, and the African Annals of Mathematics.

Around the time I left Rwanda in 1967, many countries in Black Africa were asserting their independence from colonizers. They were more focused on political reorganization than on economic reforms. By the time I reconnected with Africa in 1995, all the governments were trying to improve their economic situations. They had begun to realize that economic progress is built on technology, which depends on engineering and ultimately on science and mathematics.

Africa possesses tremendous potential for developing outstanding mathematicians and producing significant advances in research. The continent still needs much sustained help from mathematicians outside of Africa who can help native students to develop their talent and to build a mathematical life for themselves on African soil.

\section{Wilfrid Gangbo}

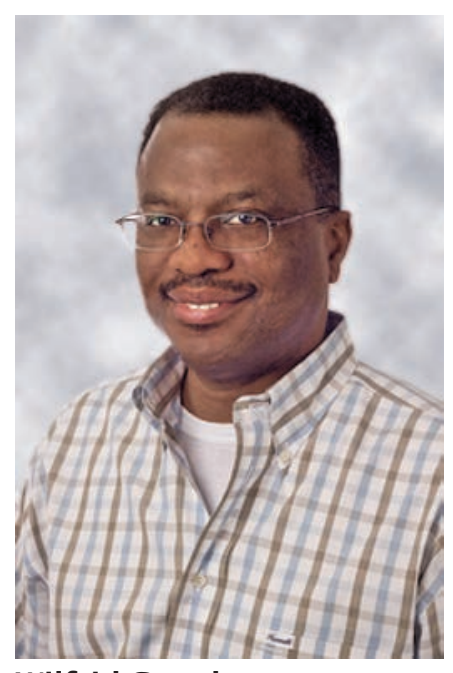

Wilfrid Gangbo

\section{Building Mathematics} in Benin

I was born in the West African nation of Benin and attended kindergarten through high school there. Benin is known for its rigor in education, which is viewed as a stepping stone into the upper middle class in a country that was not blessed, as were other African countries, with mining resources. In the 1970 s, there was great confusion about the importance of intellectuals in Benin, which had opted for a socialist government. Nevertheless, partly due to French influence, mathematics continued to be recognized as an important subject.

In the capital city of Porto-Novo, the school students who were the best in mathematics were treated like celebrities and praised by the population, including by those who never made it to high school. In the 1980s, the leading Porto-Novo high school, Lycée Behanzin, had many more high school students studying mathematics and physics than any other subject. One spectacular high school mathematics student was known in Porto-Novo as "Dr. Cosine." Many of us were motivated to uncover his strategy for success in mathematics.

In the 1970s and 1980s, Benin was full of excellent high school mathematics teachers, such as Dieudonné Quenum, who seemed to know the secret of how to instill mathematics in the heads of his students. Even people who were never in his class were fascinated by his fame, which is still talked about in some circles. My highly qualified K-11 mathematics teacher, Daniel Tetelin, who left Benin when relations with France were souring, taught us that you had to write mathematics with the greatest rigor if you wanted to pass his class. His influence drew several of us to the world of mathematics-where we have since been trapped! The ability to write detailed proofs and read mathematics carefully became a strength and made mathematics a fascination.

After those years, Benin faced a desert crossing, a devastation for mathematics. Starting in 2000, the number of students attending K-12 rose greatly, but the number specializing in mathematics rose very little, from 1364 in 2001 to just 1603 today. By contrast, the number specializing in biology rose from around 11,000 to nearly 51,000. Nowadays many mathematics instructors in Benin high schools were not undergraduate mathematics majors.

Wilfrid Gangbo is professor of mathematics at the University of California, Los Angeles. His email address is wgangbo@math. ucla.edu. 
we can

continue

to build

mathematics

in Africa.
[With help]

Benin decided to search for remedies to these problems and-along with some other African countries such as Cameroon and Senegal-has witnessed a positive slope in mathematical development. Although nobody has discovered a recipe to keep the curve concave up, we are hopeful that, with the help of the international mathematical community, we can continue to build mathematics in Africa. There are several initiatives that deserve support and development; here are two examples.

Senior mathematicians in Ivory Coast had the bright and original idea to launch a "Miss Mathematics" competition, with a monetary award. The IMSP (Institut de Mathématiques et de Sciences Physiques) in Porto-Novo decided in 2008 to create its own Miss Mathematics, which is now a national competition targeting K-9 female students who have shown superior performance in mathematics. IMSP is proud to report that today the proportion of female students in mathematics has greatly increased all over Benin. Happily, the nation of Senegal has also decided to initiate a Miss Mathematics competition.

In 2013, a team of mathematicians from IMSP won a World Bank competition to create a Center of Excellence in Mathematics. This extraordinary experiment is in its infancy and needs much constructive criticism from experienced people. Benin is fortunate to have supporters such as John Ball, Irene Gamba, Nassif Ghoussoub, Cédric Villani, and many others. Since 2014, a large number of mathematicians have spent time teaching mini-courses and participating in workshops funded by the center. Not only have students learned a great deal from the lectures by visitors, but also, and perhaps more importantly, they have been immersed in the international mathematics culture.

People often ask me, "Why do you need to invite the very best mathematicians to workshops or to teach minicourses in Africa?" I often answer, "Would Zygmund have discovered Calderón if he had not traveled to Argentina?" There is no scientifically recognized educational method to elevate the level of mathematics in a country. However, we have seen that exposing students to the very best mathematicians has had a tremendous impact in many parts of the world.

\section{Florian Luca}

\section{Fun and Adventure Teaching Math in Africa}

In 2013, I taught a three-week course in number theory at AIMS in Senegal. The course was not easy, and the pace was intense. The forty students met five days per week, two hours per day for a total of thirty hours in the threeweek period.

Students come to AIMS from all over Africa, mostly from French-speaking West African countries. Occasionally, there are students from Egypt, Sudan, or other Arabic-speaking countries or students from Eastern African countries who speak English but almost no French. In addition to courses, each student has to write a master's essay in order to graduate. I had two students interested in writing an essay with me, Bernadette Faye from Senegal and Taoufiq Damir from Morocco. Instead of giving them something to read, I involved them in some nice elementary number theory projects. The students worked very hard and learned a variety of techniques and some elementary algebraic number theory as well as gaining some basic acquaintance with multiplicative number theory and sieves. The projects led to papers coauthored by the three of us together with Dr. Amadou Tall, the local adviser of the two students, in Fibonacci Quarterly and Integers. Both students went on to pursue PhDs. Since this first experience, I have returned to teach in the AIMS network every year.

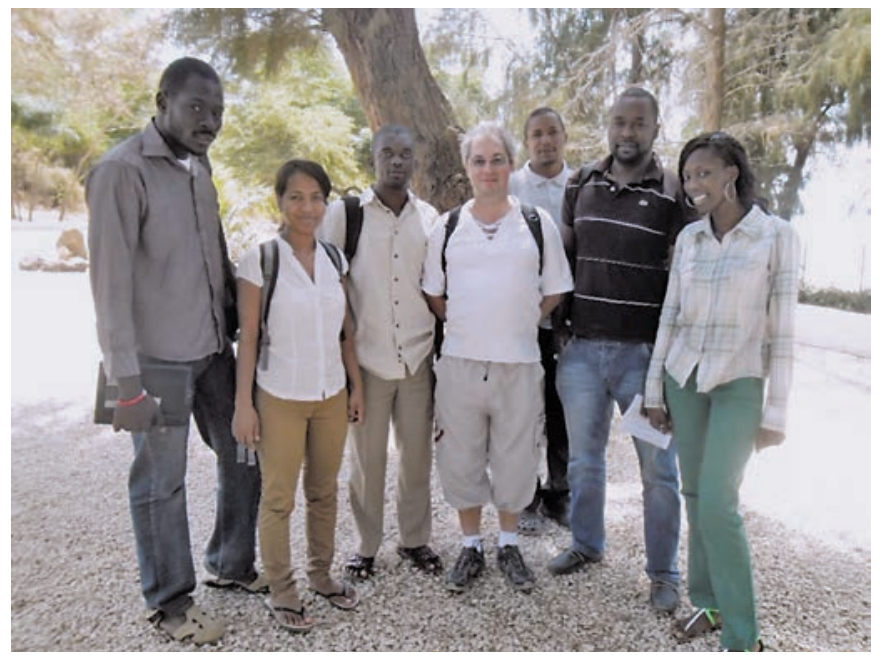

Florian Luca (fourth from left) with students at AIMS Senegal in 2013.

Traveling to and living in Africa has its challenges. For example, for my first AIMS Senegal trip, I read on the web page of the Senegalese Embassy that citizens of the European Union do not need visas. I hold a Romanian passport, but at that time Senegal was not aware that my home country was a member of the European Union. As a

Florian Luca is professor of mathematics at the University of the Witwatersrand and an associate editor of the Notices. His email address is Florian.Luca@wits.ac.za. 
consequence, I was denied boarding my flight from Washington, DC, to Johannesburg because it had a stopover in Dakar, Senegal. If you are kicked off a plane for not having a visa for your destination country, maybe Washington, $\mathrm{DC}$, is the best place for it to happen, since every nation has consular representation there. So I asked the airline to move me to the next day's flight and ventured out into the January snow in T-shirt and shorts (I was traveling between Mexico and Senegal so did not have a coat). The next day I visited the Senegalese Embassy, convinced them to give me a visa, and made the flight that evening.

Every time I have traveled to Africa my luggage has arrived at least one week after I did, so for days I'd function modulo two, with the green T-shirt on even days and the blue T-shirt on odd days, washing them every evening and letting them dry in the hot African nights. While in Ghana in 2013, unwisely having made the decision not to take my malaria pills-believing that malaria is something that happens only to other people-I got malaria and had to be treated at the local hospital in Cape Coast. The staff of AIMS Ghana took good care of me then and during all my trips to AIMS Ghana in various ways, including quarreling with the local traffic police and recovering from them my driver's license, which had been confiscated at a police roadblock because it was in a language other than English.

Such stories show that life in Africa poses challenges, but that is part of the experience of teaching and living there. I hope my story will convince you that there is great fun and great adventure to be had by teaching in Africa and involving students in your research projects.

\section{Mathematicians of the African Diaspora}

In 1997, Scott Williams of the University of New York at Buffalo launched a website called Mathematicians of the African Diaspora." The home page of the site says that Williams started the site in order to counter negative stereotype about black people "by exhibiting the accomplishments of the peoples of Africa and the African Diaspora within the Mathematical Sciences." The site supplies biographical information about hundreds of mathematicians of African descent.

www . math . buffa1o.edu/mad

\section{Nancy Ann Neudauer}

\section{Learning to Eat Soup with My Hands}

Four years ago I had never been to Africa. I had never planned to go to Africa. Now I can't seem to stop going to Africa-I've been eleven times to six countries, with plans to visit more. How did this happen? I was first invited by Rob Beezer of the University of Puget Sound, who had taught several courses at AIMS, to design and teach a course with him at AIMS South Africa. Rather than restrict my involvement to a single visit, he suggested an ambitious plan whereby I'd apply to the Fulbright Specialist Roster and return during my sabbatical the following year to teach at two AIMS centers. I did return on sabbatical, teaching courses at three of the AIMS centers, and went again later that year to supervise thesis projects. Four years and three Fulbright Specialist grants later, I'd taught at five of the six existing centers. Sometimes you take a step in a direction that unexpectedly changes your course.

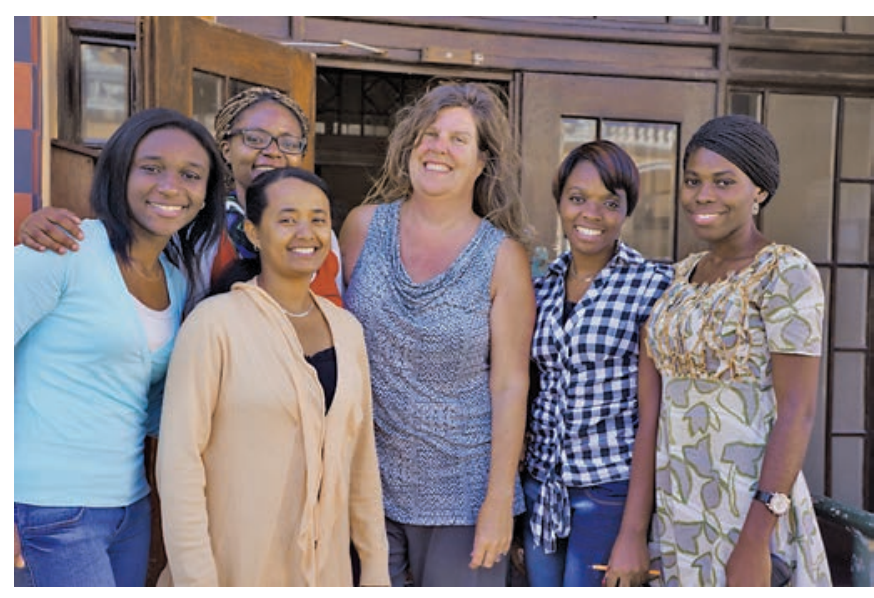

Nancy Ann Neudauer (fourth from left) gave a course at AIMS in South Africa in January 2014. Here she poses with some of her students, as well as the tutor for the course (third from left), Martha Kamkuemah, who is from Namibia and is currently working on her PhD at Stellenbosch University.

Established in Cape Town in 2003, AIMS has expanded to include centers in Cameroon, Ghana, Rwanda, Senegal, and Tanzania. Students come to AIMS from all over Africa for an intensive, one-year structured master's program. All of the courses are taught by visiting lecturers, with topics and expertise changing from year to year. The goal is to prepare the students for further graduate study in Europe, the United States, Canada, and Africa. The guiding philosophy is that Africa cannot be just consumers of mathematics; Africa must be producers of mathematics.

What is it like for an AIMS lecturer? The lecturers live and eat with the students. Someone new is always arriving

Nancy Ann Neudauer is a professor of mathematics and computer science at Pacific University, Oregon. Her email address is nancy@ pacificu.edu. 
a revolving door of researchers and lecturers from around the world or departing, so there is an incredibly vibrant atmosphere-a revolving door of researchers and lecturers from around the world, in addition to dedicated teams of permanent staff and directors. All classes are three weeks, with students taking two at a time. The first few blocks focus on basic skills, such as problem solving, advanced linear algebra, and TeX. This is followed by six blocks in which the instructor is expected to take the students from the basic foundations of a field to research-level problems in just three weeks. Finally, the students spend several months conducting independent research and writing a thesis. While all of the students have a bachelor's degree in a mathematical science, this is broadly defined, so many have neither seen formal mathematics nor ever written a proof.

Beezer and I designed and taught a course called "Designs, Matroids, and Graphs," which I have since refined and taught at several AIMS centers. We had to think radically differently about what we were teaching, not having a full semester to work through a book or slowly build up ideas. We needed to pare down to the material that was essential to get the students to a point where they could understand advanced results and open problems. Introducing students to new areas of mathematics and getting them up to current problems in several fields, in just three weeks, was a challenge for us as well as them!

I can't talk about Africa without mentioning the food. Yams, cassava, or maize, pounded to a powder and cooked into a mass-ugali in Tanzania, fufu in Ghana, couscous in Cameroon, and pap in South Africa-are universal staples that I learned to employ to pick up bits of chicken or fish heads. I even learned to scoop up soup with my hands. The students are always surprised, exclaiming, "You're eating with your hands! Like we do." I was amazed that this extremely high-carbohydrate diet, with very little protein, fresh vegetables, or fruit, could sustain the students in the intensive and demanding AIMS program. While there are some common themes to food in Africa, there are many regional differences. One of the few complaints I ever heard from the students-despite the frequent lack of internet, power, and water, despite the heat, despite the lack of books and resources we take for granted-was about the food. It was not like the food in their home countries.

What are the challenges? Everyday things we take for granted are either absent or severely compromised, but cannot be used as excuses to stop studying.

Electricity: We watched the students practice their presentations at the board illuminated by only one dim light in the back of the room because of problems with the wiring. There are often scheduled-and unscheduledpower outages.

Internet: On the days it works, it is excruciatingly slow.
Water: I wondered at first what the large vat of water in my bathroom was for. And I wondered about the bucket. I soon found out that the water from the taps frequently doesn't flow-and was not for drinking. Living for a month at a time in places where 30 percent of the population makes less than US $\$ 1.25$ a day and the GDP is under US $\$ 3,000.00$, yet everyone needs to buy drinking water and other necessities, helped me to understand how incredibly adaptable and resilient human beings are. The students epitomize this.

What keeps me coming back? This has been one of my most rewarding professional experiences. I was motivated by a professional duty and the opportunity to work with graduate students, which was new for me since my own school has only undergraduates. I also hoped to have a positive impact on the student experience. I had not anticipated that the more profound impact would be on me. I am part of an ever-expanding faculty of visiting AIMS lecturers who work tirelessly to develop the initiative in Africa, at home, and worldwide. Connections formed in this network have led to visits to my own university and to research collaborations. Principally, however, it is the students who draw me back. They have such energy and enthusiasm for learning and are very appreciative of the work I do. I leave feeling invigorated both personally and professionally. An unexpected benefit is the degree to which this undertaking has informed my own teaching, as well as my research. Teaching students who are desperate to learn but for whom one cannot assume a standard background in mathematics has helped me distill precisely what is needed to explain a result. I supervise students for whom English may be a third language. Teaching them to write mathematics well has improved my own writing, and I am much better and faster at reading and editing student work. Finally, the more I visit Africa, the more I appreciate how important female role models are. Young women and girls need to know what is possible.

When I was young, I wondered how I might change the world. Each year I teach, I realize this happens one experience at a time. 


\section{Carol Shubin}

\section{Into Africa}

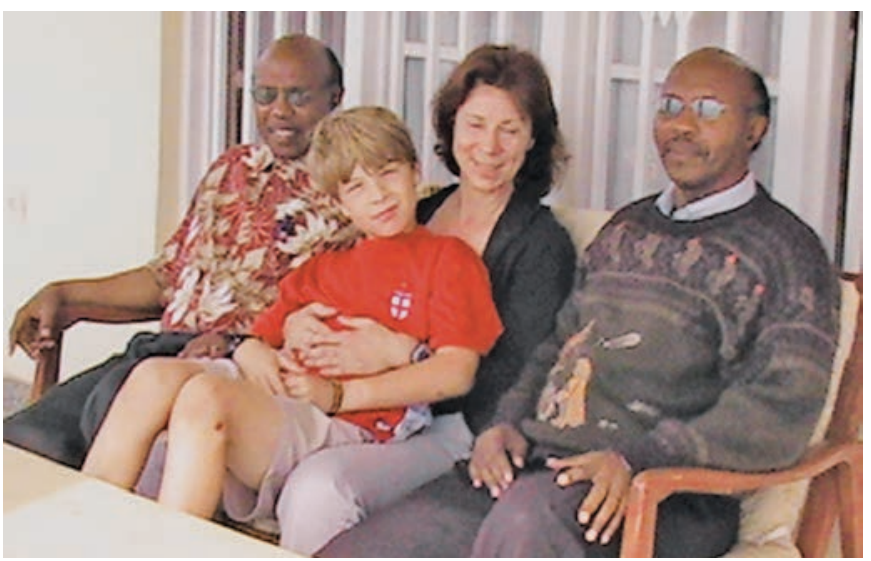

Carol Shubin in Kigali, Rwanda, holding her son James Wolff while sitting with friends Professors Paul Mwangi and Maina Maringa.

I am a professor at California State University Northridge, a large regional comprehensive university in the northern suburbs of Los Angeles. By 2006, I had wrapped up an educational grant from NASA and completed some work of my late husband, Thomas Wolff of Caltech. I wanted to do something different. I began considering "exotic" teaching locations. While searching the web, I came across a post from 1994 by Dino J. Lorenzini, Distinguished Research Professor of Mathematics at the University of Georgia, in which he stated:

The University [of Rwanda] reopened in April 1995, nine months after the end of the genocide. Before the genocide, the department of mathematics had a staff of 17. In September 1995, the staff was reduced to two graduate students, the other members being either dead, in exile or refugee camps, or in jail. The teaching was done by these graduate students and by temporary visitors from Universities in neighboring countries. The University was eager for academics of all countries to come teach at the University, and will accommodate any schedule.

I might not be Angelina Jolie, but I can teach math. I decided to find out more about Rwanda, a landlocked country known as "the land of a thousand hills." I was very impressed by the Rwanda Vision 2020 plan. The country strongly supports education and the development of STEM enterprises and is committed to gender equity.

I received a Fulbright scholarship to teach at the Kigali Institute of Science and Technology (KIST), now called College of Science and Technology - University of Rwanda (see Figure 2). My plan was to try to set up a version of bootcamp style courses that I had run with my NASA grant during 2000-2005. These three-week intensive courses on applied math topics included speaker identification, diffusion tensor imaging, analysis of the Northridge earth-

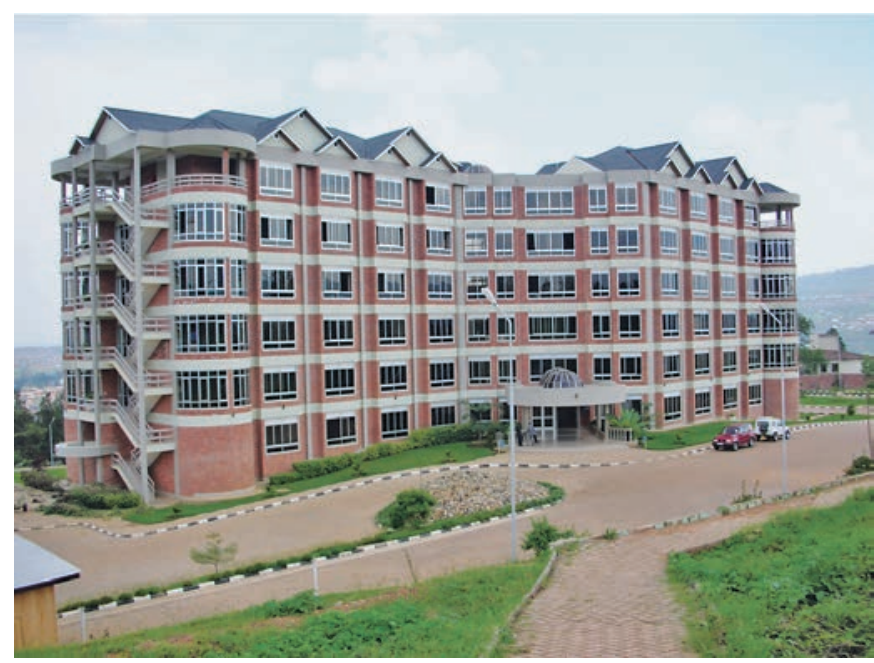

Figure 2: Pictured here is the Math Department, University of Rwanda (formerly KIST), in Kigali, Rwanda. For six months, Carol Shubin and two colleagues from her home department lived in Kigali and taught at KIST.

quake's GPS data, solar disk data, electrophoresis gel data, and satellite trajectory data. I figured that the US has more data than can be analyzed, and Africa has the talent for the work. With all the available freeware, the cost would minimal. So off I went.

For six months in 2007, I lived in Kigali with my children (then in the fourth and sixth grades); a CSUN graduate student, Jennifer Wright; and two CSUN math faculty, Werner Horn and Susan Taylor, who were on sabbatical leave. There was a need for basic instruction, so I found myself teaching several large sections of calculus. Some of the large classrooms had small blackboards and poor acoustics and lighting, making it quite difficult for students to follow the lectures.

The hardships many of the students endured to get to KIST impressed me greatly. Although a large percentage of them had been educated in French, they were expected to take courses in English with little preparation. Most of the students had received their entire education, from K-12 to college, without ever possessing a textbook. Nonetheless, I gave the same calculus course that I give at CSUN, and the students did about as well. In fact, they had stronger algebraic skills.

The following year I received a grant from the African Mathematics Millennium Science Initiative to come back. I had designed several online courses, and five KIST students tested two of them. Unfortunately, there were a lot of problems with students being able to access the internet to complete the courses. I ended up sending them money so that they could complete the work at internet cafes. I am still in touch with some of my KIST students who went on to earn advanced degrees in South Africa. I helped one student pay for college at a private university in Ohio.

Not only was the teaching experience very intense, but there is a strong bonding with other visiting instructors. Cornell math department chair Ravi Ramakrishna and I 
had many lively discussions over dinner about our observations and ideas. Following his three-month stint at KIST in 2009, he became a Tours of Purpose volunteer in Uganda, teaching a math class at Makerere University (see Figure 3). He also gave two three-week courses at AIMS South Africa. He too found the experience addictive.

In 2011, Irina Zlotnikova, my former officemate at KIST, came to visit CSUN. Her interest was in programs that focused on poverty eradication and education in Africa using information and communications technology. She had an opportunity to visit our College of Education and interact with math faculty. Later Irina invited me to the Nelson Mandela African Institution of Science and Technology (NM-AIST) in Arusha, Tanzania (2014). I was extremely impressed with the institute and enjoyed giving some talks.

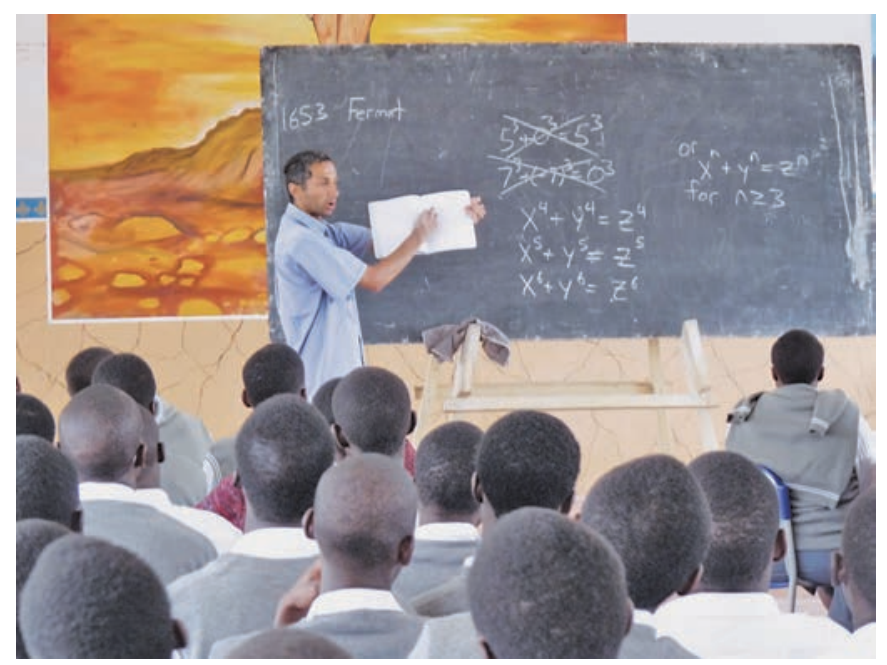

Figure 3: Ravi Ramakrishna lecturing in Uganda.

Ramakrishna is chair of the mathematics department and Stephen H. Weiss Presidential Fellow at Cornell University. Following his three-month stint at KIST in Kigali, Rwanda, in 2009, he became a Tours of Purpose volunteer in Uganda, teaching a math class at Makerere University. He also gave two three-week courses at AIMS South Africa.

During a 2014 visit to the NM-AIST, I connected with Eunice Mureithi from the University of Dar es Salaam and Josephine Kagunda from the University of Nairobi. They were active in organizing the CIMPA ${ }^{3}$ Research School on Mathematical Modeling and Analysis of Complex Systems, held in Kenya during summer 2015. Although I was not able to attend, CSUN's College of Mathematics and Science and provost's office donated US $\$ 5000$ for students to attend the program. In 2016, CSUN hosted Josephine Kagunda for three months. She worked on several papers and co-taught a senior-level seminar on disease modeling. During summer 2016, CSUN students began collaborating with University of Nairobi students on several projects stemming from the CSUN seminar. In August 2016, I vis-

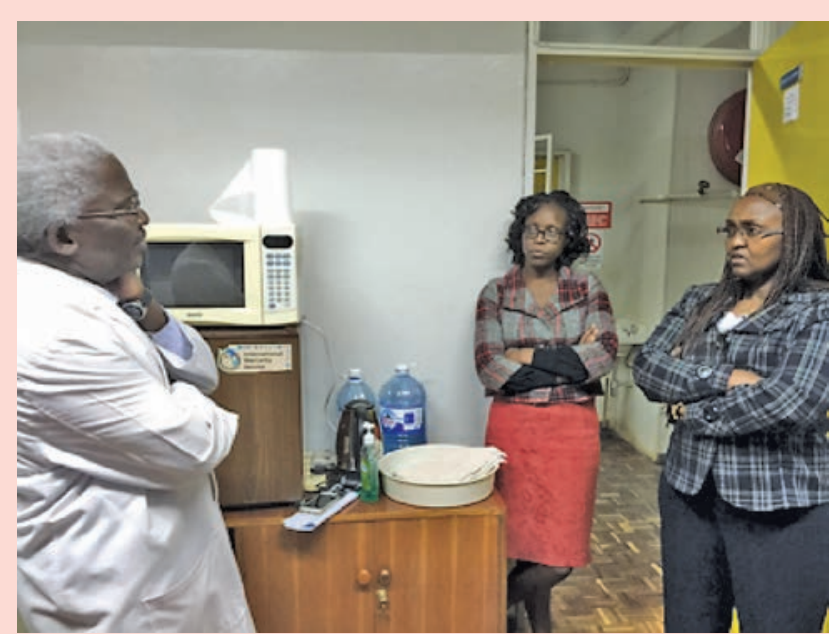

In August 2016 Wandera Ogana (left) talks with Josephine Kagunda (right), who like Ogana is in the School of Mathematics at the University of Nairobi, and student, Marilyn Ronoh.

\section{Wandera Ogana, Chair of IMU Commission for} Developing Countries

Wandera Ogana, professor of mathematics at the University of Nairobi, has been on the Commission for Developing Countries of the International Mathematical Union since 2011 and is currently serving a four-year term as CDC chair. His extensive work on building mathematics in Africa includes serving as secretary/ executive director of the African Mathematics Millennium Science Initiative.

Born in Kenya in 1946, Ogana received his bachelor's degree in mathematics from the University of East Africa in Nairobi in 1970. After a year teaching secondary school, he went to Stanford University, where he received his $\mathrm{PhD}$ in applied mechanics in 1975 , with a dissertation about transonic flows written under the direction of John Spreiter. After a year as a postdoctoral researcher at the NASA Ames Center in California, Ogana returned to Kenya to join the faculty of the University of Nairobi.

Ogana's research centers on computational fluid dynamics, particularly the application of boundary element methods to solving transonic flow problems. He has also developed mathematical models in ecology, wind energy assessment, and the impact of climate change on infectious diseases. He is a Fellow of the African Academy of Sciences and of the Kenya National Academy of Sciences and is Vice President (East Africa) of the African Mathematical Union.

Ogana has an unusual sideline: He writes fiction. His first novel, Hand of Chance, written while he was still an undergraduate, was published in 1970. He has since written three other works of fiction, the latest being A Family Affair, published by the Jomo Kenyatta Foundation in 2011.

${ }^{3}$ Centre International de Mathématiques Pures et Appliquées 
ited the University of Nairobi, where graduate students are mentoring our undergraduates' projects.

Mathematics is on the rise in Africa. I feel revitalized to participate in even a small way. I am so grateful to many people who have opened my mind and heart.

\section{Cédric Villani}

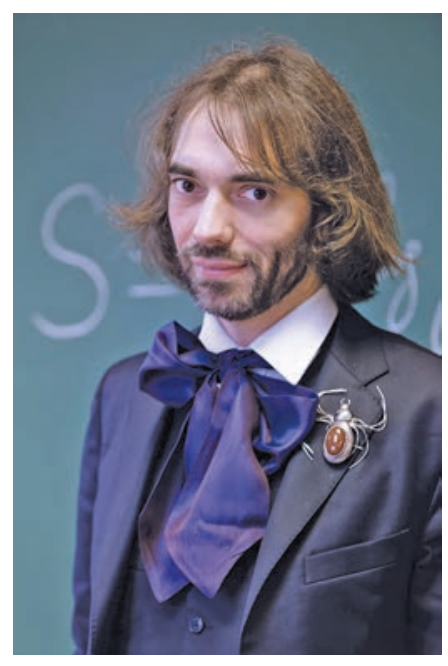

Cédric Villani

\section{Falling in Love with Africa}

My interest in mathematics in Africa started with my friend and fellow contributor here Wilfrid Gangbo, a brilliant African mathematician who is now a professor at the University of California, Los Angeles. I first met him in 1998 in Atlanta, when he was at Georgia Tech. He arranged for me to spend a semester teaching in Atlanta, which was a very important step in my career. Usually when we speak about north-south cooperation, we think of north helping south. In my case, the beginning of my career was strongly helped by this African mathematician.

In 2010, I attended a conference Wilfrid had organized in Benin. At that time, I had heard about AIMS, and as director of the Institut Henri Poincaré, I had been asked to participate. My reply was, "Let's be cautious, we don't know what this is...." But as soon as I returned from the Benin conference, my reaction was: "Math in Africa-I have to do something. It will be complicated, but it is important. It is a mission." Soon after that, I began traveling regularly to Africa. I have made eight trips to Senegal, where I participated in the launching of the AIMS center in M'Bour, as well as four trips to Cameroon, three to Benin, and one to Rwanda.

With Africa, there is a "before" you have been there and an "after." Africa has a special atmosphere. Time flows in a different manner from Europe or the US. The contacts are closer, there is a special way people talk and interact. If you are open to it, you are likely, as I did, to immediately fall in love with the whole continent.

Developing mathematics in Africa is a long-term goal. There is an appetite for mathematics, and the students are eager to learn. In a few decades, I believe Africa will

Cédric Villani was director of the Institut Henri Poincaré until 2017, when he was elected as a member of the French National Assembly. be a reservoir of students who want to improve their status through study and knowledge. For this to happen, infrastructure is crucial. Setting up internet connections is not sufficient. Facilities are needed, but so are local human networks. You need competent administrators who will make the enterprise grow and who will keep it in resonance with local conditions.

Africa is an enormously diverse continent, with many different cultures and educational systems. Some countries have huge numbers of students, and others have very few. But they all face the problem of identifying and nurturing their best students and giving them access to opportunities.

When I have taught in Africa, I can stay for a maximum of two weeks, but the courses often last longer. So I have always paired with a local professor who continued the course after I left. In the case of Senegal, I was paired with Diaraf Seck. We became close friends-we got along so well, in fact, that we made a MOOC together on differential equations. I was based in Paris and he was based in Dakar, so we had to coordinate the recording very carefully. We would mix the videos in Paris and get help from coordinators in other places. It was very complicated, but we loved it. For various reasons it did not have as much impact as we hoped, but it was a great experience.

Each time I come back to Africa, I am happy to see my friends again. My work with AIMS has been a real source of personal enrichment for me. If you measure the impact in terms of, for example, the number of the students you taught who were able to get into good $\mathrm{PhD}$ programs, the numbers are always small. But in terms of how good you feel, this work is extremely rewarding. When you meet people who participate in these adventures and have hope, it is really heart-warming.

Some of the students I have worked with have touched me deeply. One of them, Merlin Mouafo Wouodjie, is now doing his PhD in Germany. Due to a medical accident with a childhood vaccination, he is disabled-his arm and leg on one side do not function properly. He comes from an extremely religious background and signs all his email with

"God bless you." He is very gentle and kind, and, far from complaining about his disabilities, he defies them-crouching down to talk to students at the desks, or enthusiastically throwing himself towards the ball during collective volleyball games. He was absolutely the brightest student his university had ever seen, and he was always hardworking. He comes from a very poor family and could not afford to study continuously, so he would return home every year to work, and then the next year he would continue his studies. He's a typical example of a person who, given the right opportunities, could be an international-level researcher.

The goal of AIMS is to create opportunities for exactly that kind of student. At the beginning, some mathematicians and institutions viewed AIMS with suspicion, 
and some wondered about the emphasis on physics and applied mathematics. I understand the concerns but am still an enthusiastic fan of AIMS. Whatever criticisms there have been can be taken constructively and will help improve the project. I have been helping AIMS as much as I can in the past few years and am now a member of the scientific board.

To build a network that can identify excellent students takes years and requires subtlety and insight. Cultural and linguistic concerns have to be taken into consideration. There are hundreds, if not thousands, of dialects in Africa. And then there are the communication languages, mainly French and English, which were mostly imposed by the colonizers. There are big differences in the culture of the colonizers, and this influenced the teaching of mathematics in Africa. You can do a respectable career throughout Africa speaking only French, but as soon as you go to the international level, English prevails. The linguistic issue of French versus English has to be taken very seriously in the development of math in Africa, at least for some time to come.

Among the institutions that are well trusted in Africa is the Abdus Salam International Center for Theoretical Physics, based in Trieste, which is launching a new branch in Rwanda called the East African Institute for Fundamental Research. Another is Centre International de Mathématiques Pures et Appliquées (CIMPA), which was founded in Nice in 1978. CIMPA funds local mathematics initiatives in developing countries across the world, including Africa.

For those who are interested in helping the development of mathematics in Africa: Do it! Africa is like no other place. World society has a big stake in Africa's political, economic, and technological development. It's vitally important that science and mathematics take their part in that construction.

The single biggest mistake we can make is to see helping Africa as a charity act: "I am rich. Let me give you a little bit of my wealth." The right attitude is: "We are all in the same boat. I can do good for you, you can do good for me. We have a lot to share." I strongly advise mathematicians to participate in existing initiatives, such as AIMS, or the World Bank centers, or the projects funded by the Simons Foundation. These initiatives need to be reinforced and to gain in efficiency and recognition. Systemic thinking is important.

The politics of many countries in Europe and other parts of the world has become much too inward looking. This makes it all the more urgent that we who work in mathematics, science, and culture take up our duty to try to bring diverse people of the world together for the common good.

\section{Michel Waldschmidt}

\section{Teaching in Africa}

I taught mathematics to African students in various circumstances, including through research schools of the Centre International de Mathématiques Pures et Appliquées (CIMPA) and through African Mathematical Schools, which are jointly supported by CIMPA and the African Mathematical Union. These courses took place in Algeria, Morocco, Mauritania, Mali, Ivory Coast, Benin, Senegal, Congo Kinshasa, Cabo Verde, and Ghana.

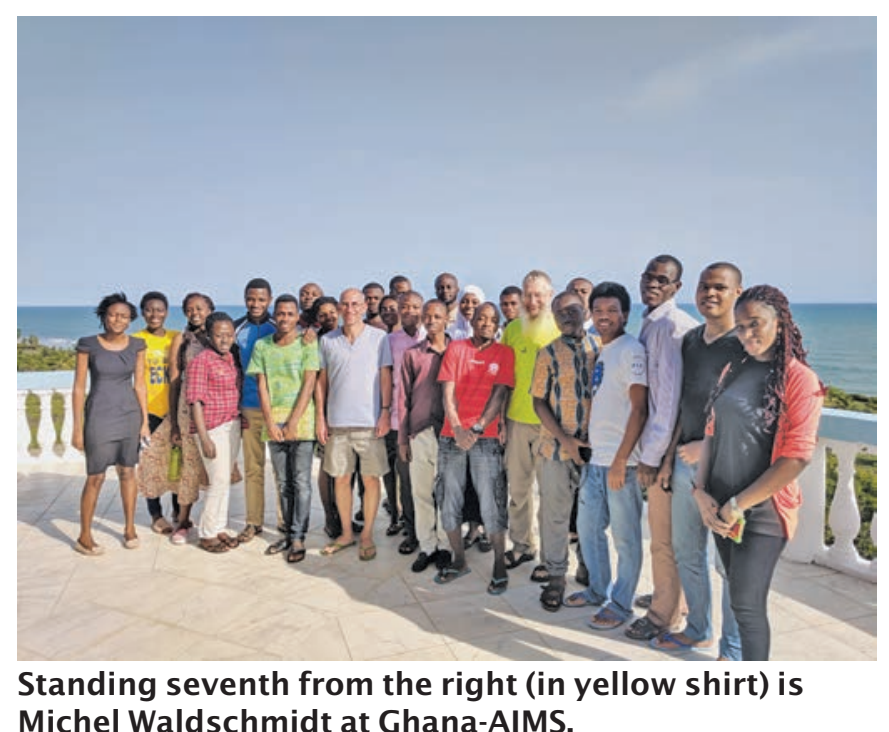

I often meet the same students from Africa at different places, including CIMPA Research Schools and African Mathematical Schools. These students are among the ones who are most enthusiastic about learning and improving their skills. In Africa, as in other places, one cannot avoid being asked, "What is this useful for?" This question might be asked any time, for instance right after the teacher has completed a proof of a beautiful result that he or she considers a work of art!

Most students have a weak background but are eager to learn. A motivation for many of them is to get a scholarship and pursue their studies abroad, usually in the US. Very often, they will end up as a teacher in a small college in the US and give up research. However, some of them come back and contribute to the development of mathematics in their home countries.

Through AIMS, students attend courses on a wide variety of topics, not only mathematics; this is good for enlarging the scope of their interests and for giving them a broader perspective of mathematics and related topics. They come to consider mathematics as a part of science, which is related to many different subjects. However, they gain only a superficial knowledge of each topic. A better goal might be to improve their background, which often

Michel Waldschmidt is professor emeritus in the Faculté de Mathématiques Pierre et Marie Curie. His email address is mi che1. wa1dschmidt@imj-prg.fr. 
AIMS is good for enlarging

the scope of their interests and for giving them a broader perspective of related topics. mathematics and

is not very strong. At the end of their stay at AIMS they write a memoir, which is very often for them the first experience of writing a piece of mathematical work that is not an exam or homework. The teachers play a fundamental role in the process and are one of the main components of the AIMS centers.

The teachers visit AIMS for a period of three weeks. My own experience at AIMS in M'Bour, Senegal, is that during these three weeks I taught only what I had prepared for the first week: I needed to explain basic notions that the students had never heard of before. During the first of each of these three-week periods, the students are supposed to attend all courses on various unrelated topics, including not only mathematics, but also topics ranging from theoretical physics to management. For the last two weeks they select some topics with tutorial sessions, where they have to solve exercises. Each course, except the first one, starts with a short quiz of some ten minutes, which I find a good idea for the students as well as for the tutors, who can assess what the students have understood. The fact that there is no diploma at the end is coherent with the whole process. The AIMS centers play an important role in the development of mathematics in Africa. I wish something similar could be launched in Asia, where there is also a strong need to support students who wish to become mathematicians.

\section{Photo Credits}

Photo of Augustin Banyaga by Judith Mukaruziga.

Figure 1 courtesy of Prof. Aboubacar Marcos.

Photo of Wilfrid Gangbo courtesy of Wilfrid Gangbo.

Photo of Florian Luca courtesy of Florian Luca.

Photo of Nancy Ann Neudauer courtesy of Robert A. Beezer, used with permission.

Photo of Carol Shubin by Jennifer Wright.

Figure 2 courtesy of Werner Horn.

Figure 3 courtesy of R. Ramakrishna.

Photo of Cédric Villani (c) Marie-Lan Nguyen/Wikimedia Commons.

Photo of Wandera Ogana by Carol Shubin.

Photo of Michel Waldschmidt by Seth Afari-Boateng.

Noted Resources for Sidebar (facing page)

www.cies.org/programs

2www. mathunion.org/cdc/volunteer-1ecturer-program

$\sqrt[3]{\text { www.nexteinstein.org }}$

4 www. cimpa.info/en

5 ammsi.or.ke/available-opportunities

6 www . mathunion .org/cdc/grants/imu-simons-african -fellowship-program

${ }^{7}$ https://sites.google.com/site/awmmath/programs /trave1-grants/mathematics-trave1-grants

8 https://www.carnegie.org

${ }^{9}$ Africa, Near East, and South Asia Regional Opportunities, https://www.nsf.gov/od/oise/anesa.jsp

19 www . mathunion .org/cdc/grants/african-diaspora -mathematicians-program-admp

11 friends-imu.org/graid

12 friends-imu.org/graid-donation

13 https://www. 1ms.ac.uk/grants/mentoring-african -research-mathematics

14 imomath . com/index . php?options=Pa\&mod=23\&ttn=Pan -African

15 www . i ie.org/Programs/Carnegie-African-Diaspora -Fel1owship-Program

16 africanwomeninmath.org 


\section{Ways to Get Involved}

There are many ways mathematicians at all stages of their careers can contribute to the development of mathematics in Africa. Here are some suggestions, assembled by Carol Shubin and Wandera Ogana. Ogana is professor of mathematics at the University of Nairobi and chair of the Commission for Developing Countries (CDC) of the International Mathematical Union (IMU).

Teach for a semester: Traditional ways include taking a sabbatical or applying for a Fulbright Fellowship ${ }^{1}$ to teach at an African university.

Teach in a summer school or intensive course: The IMU Volunteer Lecturer Program ${ }^{2}$ brings lecturers to mathematics departments in universities in the developing world, to teach intensive 3-4 week courses in mathematics at the advanced undergraduate or master's level. Courses for a Master of "Mathematics and Informatics" or similar subjects are also admissible. The lecturer receives funding for all living expenses, including travel.

The African Institute for Mathematical Sciences (AIMS) has launched the AIMS-Next Einstein Initiative, ${ }^{3}$ a pan-African network that offers post-baccalaureate training in the mathematical sciences to African students. AIMS centers are located in South Africa, Cameroon, Ghana, Rwanda, Senegal, and Tanzania. The academic year at AIMS centers consists of three phases: the skills, review, and research phases, each subdivided into modular three-week blocks. To teach a three-week bootcamp-style course, one can submit a structured master's course proposal to AIMS.

The Centre International de Mathématiques Pures et Appliquées (CIMPA) ${ }^{4}$ founded in France in 1978, is a nonprofit organization that aims to build mathematics research in developing countries. CIMPA supports about twenty Research Schools per year, offering research-level courses in mathematics and short-term thematic programs.

Travel Grants: The African Mathematics Millennium Science Initiative $(A M M S I)^{5}$ supports travel grants and scholarships for African master's and doctoral students to study abroad.

The IMU-Simons Africa Fellowship Program ${ }^{6}$ supports research sabbaticals for mathematicians who are from developing countries in Africa and are employed in Africa. The fellowships support travel to internationally recognized mathematical centers worldwide for collaborative research. The grants are for a limited period and cover travel and basic living costs.

The Association for Women in Mathematics ${ }^{7}$ awards travel grants on a competitive basis; they can be used for research travel anywhere, including Africa.
Grant Opportunities: The Carnegie Corporation of New York, ${ }^{8}$ a grant-making foundation, supports higher education and research in Africa, particularly Sub-Saharan Africa, with the aim of fostering Africa's knowledge-based, globally competitive economy. Carnegie funds scholars, academic institutions, and continental networks.

The National Science Foundation's ANESA program $^{9}$ provides funding to build research collaborations with African scientists and engineers and to give US students research experiences in Africa. Participation of junior investigators from both the US and the host country is strongly encouraged. Support is available to all disciplines funded by the NSF.

Activities of the IMU: The African Diaspora Mathematicians Program ${ }^{10}$ of the IMU's Commission for Developing Countries taps the expertise of Diaspora mathematicians, in a more formal manner, in order to provide additional staff and support to mathematics departments.

The Graduate Research Assistantships in Developing Countries (GRAID), ${ }^{11}$ recently launched by the IMU, allows graduate students to study mathematics full-time when no other fellowships are available. The effort is funded by donations to the Friends of the IMU. ${ }^{12}$

The IMU's Mentoring African Research in Mathematics $(M A R M)^{13}$ program links African academics with their counterparts in the United Kingdom and Europe, via professional mentoring partnerships. The program is implemented through collaboration of the IMU, the London Mathematical Society, and the African Mathematics Millennium Science Initiative.

Other ways to connect: The Pan-African Mathematics Olympiads ${ }^{14}$ are events of the African Mathematics Union, organized each year in an African country. Promising students who are less than twenty years old are invited to compete.

The Carnegie African Diaspora Fellowship Program ${ }^{15}$ allows institutions in several African countries to host an African-born scholar to work on projects in research collaboration, graduate student teaching/mentoring, and curriculum development.

The African Women in Mathematics Association ${ }^{16}$ was established in 2013 to promote women in mathematics and encourage girls to study the subject.

You don't need to work through a foundation or an agency: You can reach out to African colleagues on an individual, informal basis and ask how you can help. 